\title{
The quality assessment of family physician service in rural regions, Northeast of Iran in 2012
}

\author{
Ali Vafaee-Najar ${ }^{1}$, Zohre Nejatzadegan $^{2}$, Arefeh Pourtaleb ${ }^{3}$, Shahnaz Kaffashi ${ }^{4}$, Marjan Vejdani $^{5}$, \\ Yasamin Molavi-Taleghani ${ }^{2}$, Hosein Ebrahimipour ${ }^{1, *}$
}

\begin{abstract}
Background: Following the implementation of family physician plan in rural areas, the quantity of provided services has been increased, but what leads on the next topic is the improvement in expected quality of service, as well. The present study aims at determining the gap between patients' expectation and perception from the quality of services provided by family physicians during the spring and summer of 2012.

Methods: This was a cross-sectional study in which 480 patients who referred to family physician centers were selected with clustering and simple randomized method. Data were collected through SERVQUAL standard questionnaire and were analyzed with descriptive statistics, using statistical T-test, Kruskal-Wallis, and Wilcoxon signed-rank tests by SPSS 16 at a significance level of 0.05 .

Results: The difference between the mean scores of expectation and perception was about -0.93 , which is considered as statistically significant difference $(P \leq 0.05)$. Also, the differences in five dimensions of quality were as follows: tangible -1.10 , reliability -0.87 , responsiveness -1.06 , assurance -0.83 , and empathy -0.82 . Findings showed that there was a significant difference between expectation and perception in five concepts of the provided services $(P \leq 0.05)$.

Conclusion: There was a gap between the ideal situation and the current situation of family physician quality of services. Our suggestion is maintaining a strong focus on patients, creating a medical practice that would exceed patients' expectations, providing high-quality healthcare services, and realizing the continuous improvement of all processes. In both tangible and responsive, the gap was greater than the other dimensions. It is recommended that more attention should be paid to the physical appearance of the health center environment and the availability of staff and employees. Keywords: Expectations and Perceptions, Family Physician, Gap Analysis, Service Quality

Copyright: @ 2014 by Kerman University of Medical Sciences

Citation: Vafaee-Najar A, Nejatzadegan Z, Pourtaleb A, Kaffashi S, Vejdani M, Molavi Taleghani Y, et al. The quality assessment of family physician service in rural regions, Northeast of Iran in 2012. Int J Health Policy Manag 2014; 2 : 137-142. doi: 10.15171/ijhpm.2014.35
\end{abstract}

Article History:

Received: 24 December 2013

Accepted: 5 April 2014

ePublished: 10 April 2014

*Correspondence to

Hosein Ebrahimipour

Email: ebrahimipourh@mums.ac.ir

\section{Introduction}

World Health Organization (WHO) in Declaration of Alma Ata 1978 defined Primary Health Care (PHC) as an appliance to achieve health for all by the year 2000 (1). PHC is an important and vital part of any country's functionality and it is implemented by family physician team in the rural and urban areas in Iran. Family physicians are healthcare providers who emphasize on disease prevention and health promotion (2). In the family physician plan, general practitioners and their health teams are totally responsible to deliver health services for patients and their families and even after referring the patients to the specialists, they have responsibility for patients' follow up (3).

Implementing family physician program and setting up health teams on healthcare centers made considerable changes in providing healthcare services to rural areas (4). Family physicians play an essential role and act as a communicational bridge between people and healthcare systems in providing healthcare services efficiently (5). In the family physician plan, it is expected that along with the increase in the quantity of services, the quality would be improved as well (6). In this plan, we need to measure and improve Service Quality (SQ) as one of the efficient and important common factors to assess the success in healthcare services (6). Due to the greater importance of SQ for both service provider and consumer, the quality of service has a critical role in designing services and marketing (7).

SQ has been defined as the difference between customers' needs and what they really receive (8). Researchers have been studying the SQs for more than two decades, some studies have assessed the relation between SQs and customers satisfaction (7-9). Laith and Feras' study showed that high level of SQs leads to higher customer satisfaction and also SQs would preserve current customers, attract new clients, reduce costs, and eventually increase the benefits (9).

The most common tool used for the evaluation of SQs is SERVQUAL, which was developed by Parasuraman et al. based on the services quality gap theory $(6,10)$. SERVQUAL has been widely used in many service industries including banking, education, hospitals, dentistry, and healthcare (6). In this tool, the SQs is evaluated through comparing customers' expectation and perception from different aspects $(6,11)$. In detail, customers' expectation is in fact the idea about the offered services, which is used as a standard when customer evaluates the service provider's function.

Customer's perception means how customer evaluates the received services. Perceived quality is part of the attitude, which is related to satisfaction; and is the outcome of 
comparing expectation and perception from function. Customers' perception is always in relative relations with their expectation $(6,11)$. Many studies aimed at evaluating the gap between patients' expectation and their perception by SQs in hospitals and healthcare centers $(4,12,13)$.

Results of a study conducted to assess the satisfaction of the participants from family physician services In Iran (2009), indicated that among a total of 11253 participants, $80.6 \%$ expressed high and very high satisfaction. The average satisfaction rate in Khorasan-Razavi province from family physician plan was $46.8 \%$ (14). In other studies conducted in Malaysia and Greek, participants were not satisfied about the SQs in the healthcare settings and hospitals $(12,15)$. Results of a study conducted in Jordan in 2011 showed that the patients' perception of the healthcare quality has strong and positive effects on their trust and satisfaction. Moreover, patient satisfaction had an important and positive mediating effect on the relationship between the quality of healthcare services and the patients' trust on healthcare provider (9).

In another study to evaluate the quality of health services in health centers of Zanjan district of Iran (2012), results indicated that there was a negative quality gap at five SERVQUAL dimensions. The most and least negative quality gap mean scores were in reliability dimension $(-2.1)$ and tangible (-1.13), respectively (6).

The results of another study In Tehran to evaluate the effect of the SQ on Patient loyalty revealed that the patients' experience in relation to the private hospitals' services had a strong impact on the outcomes like willingness in returning to the same hospital and reusing its services or recommending it to others (16).

Given that, this issue has drawn attention in recent years among policy-makers. As there is no sufficient evidence in Iran and other developing countries regarding this issue, the present study aimed at evaluating the expectations and perceptions about quality in family physicians services in Khorasan-Razavi province, Northeastern Iran in 2012.

Methods

This cross-sectional study was conducted in rural health centers in 2012. The investigated population covered the family physicians program in 4 rural health centers of Mashhad. The population was selected using a Cluster stratified and Simple Random sampling in which 16 rural areas were included. Finally 435 of the 480 distributed questionnaires (response rate $=90 \%$ ) were filled out during the 4 months of the study. The implemented SERVQUAL questionnaire $(6,8,17)$ consisted of 2 sections: The first section was for demographic items with 7 questions. The second section consisted of 2 parts: expectations and perceptions. Each part has 22 likert scale questions-from 1 (strongly disagree) to 5 (strongly agree)-in five dimensions of reliability, assurance, tangibles, empathy, and responsiveness. The validity and reliability of the translated version of the questionnaire was confirmed in a previous study in the health centers (6). Data was collected in the field. One of the researchers, present at the place, explained the aim of the study and made patients assured of the privacy of their responses. Participants with enough education received information about the study and filled the questionnaire by themselves, for those without proper education or any other related problems, the researcher read the questions and helped them to select their answers. Data was analyzed using SPSS 16.5 (SPSS Inc., Chicago, IL, USA) and descriptive statistics (frequency, percentage, mean, and standard deviation), T-test and Kruskal-Wallis tests. The Wilcoxon signed-rank test was used in comparing the patients' "perception" and "expectations" scores; and in analyzing such mean scores in the different groups. Mean scores of perceptions and expectations were used to compare patients' perceptions and expectations of health service quality. The gap was calculated using SERVQUAL equation: Service Quality $(S Q)=$ Perception (P) - Expectation (E). The significant level was 0.05 in all tests.

\section{Results}

Among the study population (435 patients), $89 \%$ were female, $34 \%$ were Junior high school, $92.18 \%$ were married (response

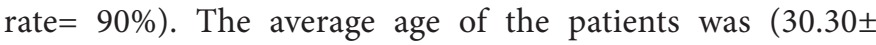
$10.37)$ years old. The mean number of visits to the doctor was $(7.58 \pm 6.25$; Table 1$)$. Table 2 shows that the mean scores of expectations were high and ranged from $4.12 \pm 0.98$ for item 22 (Having patients' best interest at heart) to $4.65 \pm 0.68$ for item 2 (Clean and comfortable environment of the health centers). Among the five dimensions of quality, the highest expectation was related to the tangible dimension $(4.53 \pm$ $0.56)$ and the lowest expectation was related to the empathy dimension $(4.27 \pm 0.71)$.

The mean score of the perceptions ranged from $3.02 \pm 1.21$ for item 4 (Modern and up-to-date equipment) to $3.97 \pm$

Table 1. Participants' demographic information

\begin{tabular}{|c|c|c|}
\hline Characteristic & & Number (\%) \\
\hline \multirow{2}{*}{ Gender } & Female & $387(89)$ \\
\hline & Male & $48(11)$ \\
\hline \multirow{6}{*}{ Number of visits } & $0-5$ & $181(41.60)$ \\
\hline & $6-10$ & $90(20.68)$ \\
\hline & $11-15$ & 39 (8.96) \\
\hline & $16-20$ & $25(5.74)$ \\
\hline & $21-25$ & $3(0.68)$ \\
\hline & $26-30$ & $7(1.60)$ \\
\hline \multirow{6}{*}{ Age } & $<20$ & 60 (13.79) \\
\hline & $21-30$ & $203(46.66)$ \\
\hline & $31-40$ & $106(24.36)$ \\
\hline & $41-50$ & $39(8.96)$ \\
\hline & $51-60$ & $12(2.75)$ \\
\hline & $>60$ & $8(1.83)$ \\
\hline \multirow{7}{*}{ Education level } & Illiterate & $20(4.59)$ \\
\hline & Primary school & $136(31.26)$ \\
\hline & Junior high school & $148(34.02)$ \\
\hline & High school diploma & $112(25.74)$ \\
\hline & Associate Degree & $9(2.06)$ \\
\hline & Bachelor degree & $6(1.37)$ \\
\hline & Master degree & $1(0.22)$ \\
\hline \multirow{2}{*}{ Marital status } & Yes & 401 (92.18) \\
\hline & No & $33(7.58)$ \\
\hline
\end{tabular}


Table 2. Mean level of the patient perceptions, expectations, and service gaps in five SERVQUAL dimensions

\begin{tabular}{|c|c|c|c|c|c|}
\hline \multicolumn{2}{|c|}{ Dimensions and items } & $\begin{array}{l}\text { Expectation } \\
\text { (Mean } \pm \text { SD) }\end{array}$ & $\begin{array}{l}\text { Perception } \\
\text { (Mean } \pm \text { SD) }\end{array}$ & $\begin{array}{l}\text { Quality Gap } \\
\text { (Mean } \pm \text { SD) }\end{array}$ & $\boldsymbol{P}$ \\
\hline \multicolumn{2}{|c|}{ Tangibles } & $4.53 \pm 0.56$ & $3.43 \pm 0.86$ & $-1.10 \pm 0.98$ & 0.00 \\
\hline 1. & Neatness and professional appearance of health centre staff & $4.59 \pm 0.67$ & $3.84 \pm 0.95$ & $0.73 \pm 1.06$ & 0.00 \\
\hline 2. & Sanitation of health centre environment & $4.65 \pm 0.68$ & $3.48 \pm 1.04$ & $1.16 \pm 1.27$ & 0.00 \\
\hline 3. & Visual appeal of physical facilities & $4.42 \pm 0.80$ & $3.38 \pm 1.04$ & $1.03 \pm 1.20$ & 0.00 \\
\hline 4. & Modern and up-to-date equipment & $4.48 \pm 0.81$ & $3.02 \pm 1.21$ & $1.45 \pm 1.44$ & 0.00 \\
\hline \multicolumn{2}{|c|}{ Reliability } & $4.48 \pm 0.57$ & $3.61 \pm 0.88$ & $-0.87 \pm 0.97$ & 0.00 \\
\hline 1. & Providing services as promised. & $4.44 \pm 0.81$ & $3.40 \pm 1.06$ & $1.02 \pm 1.29$ & 0.00 \\
\hline 2. & Sincere interest of personnel in solving patients' problems & $4.45 \pm 0.75$ & $3.59 \pm 1.11$ & $0.85 \pm 1.28$ & 0.00 \\
\hline 3. & Carrying out of the services right at the first time & $4.55 \pm 0.68$ & $3.59 \pm 1.08$ & $0.96 \pm 1.21$ & 0.00 \\
\hline 4. & Provision of health services at the time promised & $4.39 \pm 0.79$ & $3.51 \pm 1.06$ & $0.88 \pm 1.27$ & 0.00 \\
\hline \multicolumn{2}{|c|}{ Responsiveness } & $4.45 \pm 0.65$ & $3.39 \pm 0.95$ & $-1.06 \pm 1.06$ & 0.00 \\
\hline 1. & Keeping client records correctly without mistake & $4.58 \pm 0.66$ & $3.97 \pm 0.95$ & $0.61 \pm 1.02$ & 0.00 \\
\hline 2. & Information provided on when services will be performed & $4.49 \pm 0.73$ & $3.63 \pm 1.05$ & $0.86 \pm 1.19$ & 0.00 \\
\hline 3. & Fast and efficient service & $4.45 \pm 0.84$ & $3.15 \pm 1.13$ & $1.31 \pm 1.36$ & 0.00 \\
\hline 4. & Willingness of personnel to help the patients & $4.35 \pm 0.86$ & $3.47 \pm 1.17$ & $0.87 \pm 1.31$ & 0.00 \\
\hline \multicolumn{2}{|c|}{ Assurance } & $4.48 \pm 0.62$ & $3.68 \pm 0.90$ & $-0.80 \pm 0.99$ & 0.00 \\
\hline 1. & Accessibility of staff when needed & $4.48 \pm 0.77$ & $3.32 \pm 1.14$ & $1.16 \pm 1.32$ & 0.00 \\
\hline 2. & Staff are trustworthy & $4.47 \pm 0.72$ & $3.66 \pm 1.00$ & $0.82 \pm 1.15$ & 0.00 \\
\hline 3. & Feeling safe and secure when interacting with personnel & $4.47 \pm 0.78$ & $3.66 \pm 1.01$ & $0.80 \pm 1.18$ & 0.00 \\
\hline 4. & Knowledgeable personnel to answer patients' questions & $4.50 \pm 0.77$ & $3.60 \pm 1.06$ & $0.89 \pm 1.19$ & 0.00 \\
\hline 5. & Polite and friendly manner of personnel with patients & $4.49 \pm 0.73$ & $3.81 \pm 1.11$ & $0.67 \pm 1.23$ & 0.00 \\
\hline \multicolumn{2}{|c|}{ Empathy } & $4.27 \pm 0.71$ & $3.47 \pm 0.97$ & $-0.79 \pm 1.08$ & 0.00 \\
\hline 1. & Special attention to each of the patients & $4.32 \pm 0.81$ & $3.54 \pm 1.02$ & $0.78 \pm 1.25$ & 0.00 \\
\hline 2. & Operating hours appropriate to all patients & $4.35 \pm 0.80$ & $3.50 \pm 1.13$ & $0.85 \pm 1.31$ & 0.00 \\
\hline 3. & Attention to the patient's beliefs and emotions & $4.27 \pm 0.84$ & $3.47 \pm 1.09$ & $0.80 \pm 1.24$ & 0.00 \\
\hline 4. & Having patients' best interest at heart & $4.12 \pm 0.98$ & $3.36 \pm 1.20$ & $0.75 \pm 1.39$ & 0.00 \\
\hline 5. & Understanding specific needs of patients & $4.25 \pm 0.92$ & $3.50 \pm 1.15$ & $0.75 \pm 1.35$ & 0.00 \\
\hline \multicolumn{2}{|c|}{ Total Service Quality } & $4.45 \pm 0.54$ & $3.52 \pm 0.83$ & $-0.93 \pm 0.91$ & 0.00 \\
\hline
\end{tabular}

0.95 for item 9 (Keeping client correctly without mistake). Among the five dimensions of quality, the highest perception was related to the assurance dimension $(3.68 \pm 0.90)$ and the lowest perception was related to the responsiveness dimension $(3.39 \pm 0.95)$.

The total expectation mean was $(4.45 \pm 0.55)$ and the total perception mean was $(3.52 \pm 0.83)$. Among the five dimensions, the highest gap was for tangibility $(-1.10)$ and the lowest gap was for empathy (-0.79). There was a significant difference between patients' perceptions and expectations at all quality dimensions $(P \leq 0.05)$. Our results also demonstrated that there was no significant difference between the SQ dimension gaps and educational level, and marital status $(P \geq 0.05)$. However gender showed differences in some dimensions as follows: gender and responsiveness $(P=0.00)$, reliability $(P=0.03)$, assurance $(P=0.01)$, and empathy $(P=0.03)$.

\section{Discussion}

This cross-sectional study was performed with the aim of evaluating the expectations and perceptions about quality in family physicians services in Khorasan-Razavi province, Northeastern Iran in 2012.
This study showed that patients' perception was lower than their expectation. This finding is consistent with other national and international studies $(6,11,13,15)$. The overall gap score was -0.93 and there was a significant difference between the expectation and perception about quality of provided services in family physician plan $(6,11-13,15,18-21)$.

There were negative quality gaps at five SERVQUAL dimensions in this study about family physician plan. These differences were observed in SQs for all dimensions including tangible, empathy, assurance, reliability, and responsiveness; which means patients' expectations were not met at any of health services dimensions (6,22). Hospital assessment in Kerman by SERVQUAL also showed a negative gap between patients' perceptions and expectations in all five dimensions of quality in healthcare services (13). On the other hand, this result contrasted with another investigation in a Malaysian study in which the patients' perception was higher than their expectation (21). This discrepancy could be the result of evaluating the private hospitals in Malaysia, as the differences in quality of services are more apparent in public hospitals (22). Findings showed that the most and least quality gap scores existed in tangible, responsiveness, reliability, assurance, and 
empathy dimensions, respectively.

As we mentioned above, the most important issue was related to tangible dimension in following aspects; personnel appearance, cleanness and adornment, environment cleanness, having upto-date medical equipment, and amount of time spent by the personnel for visitors, which are similar to some other studies $(23,24)$. Other study indicated that the physical environment of the health center can affect the patient's perception (24), and medical equipment are one of the physical factors increasing patients' satisfaction (25). Therefore, it is recommended that healthcare centers managers pay more attention to physical environment, personnel appearance, and renovation of the equipment, which would positively affect the patients' mental evaluation from the quality of health services.

In this study, we observed the second difference which existed in the responsiveness dimension score. This includes: providing patients with exact time of performing a service, providing a service fast without any waiting times, personnel enthusiasm for helping the patients, availability of personnel in the case of need, which is similar to another national study in healthcare centers based on the client's expectation and perception (6). It is recommended to reduce the waiting times for providing services, improve personnel willingness to help customers, and promote organizational responsiveness with effective management of human resources. Prompt attention and waiting time is an important factor in responsiveness dimension; while in Indonesia long waiting time for the treatment seemed to be the main reason for patient dissatisfaction in Governmental health center (26). Another study about family practice clinic showed that actual waiting times were usually longer than those estimated by the patient, and total waiting times were considered reasonable (27). Making a proper appointment with time schedule can improve this situation and patients would be more satisfied if visiting time becomes more patient-centered, admitting patients faster, and regard patients' opinions about the number of weekly visits (28).

The third difference existed in the reliability dimension about the ability to perform the services accurately and dependably and keeping patients' health records which is consistent with Dean's study (23). Telling the truth is one of the most important facts that increase reliability between personnel and patients. Telling the truth in medicine means providing patients with appropriative information to make informed decision about their healthcare, other aspects of their life and to inform them about the condition they are in (25). Usually, patients have stress about their illness, providing them with right and on time information, disease stages and time period, can reduce their stress and decrease the gap in the reliability dimension. These findings emphasize that patients should receive prompt and timely care, be educated about their medical options, and feel that they have been treated with courtesy and respect.

The fourth difference which existed in assurance dimension includes: patients' trust to personnel, feeling safe and being relax when contacting personnel, personnel courtesy and humility, and their knowledge and skills in respond to patients' needs which is consistent with Mohammadi et al. study in health centers of Zanjan (6). Quality assurance is all the necessary activities performed to preserve and improve quality (25), therefore healthcare centers have to continuously assess the quality of their services. Well-trained personnel and other support staff also play vital roles in providing support to patients' feelings of assurance and safety.

The least difference existed in empathy dimension which represents the sympathy of health service provider and understanding the patients' problems and needs. The necessity of paying attention to each patient, scheduling the appropriate time for referring to the center, special attention to values and emotions of patients, and personnel's real interest to patients are all consistent with Jenaabadi et al. study (25). It has been stated that the more empathy from the personnel, the better the patients' satisfaction would become (29). Performing education classes especially psychology classes, and teaching aspects of individual characteristics to personnel can decrease this gap.

\section{Limitation}

The most important limitation of the present study was the fact that since health team was working beside healthcare team in health centers, it was difficult for the patients to differentiate them, and patients evaluated both teams when responding to the questionnaire. To overcome this limitation, the researcher was presented personally in place and tried to distinguish the targeted group (health team) for the responders. Another limitation of this survey was about the sample population as the female respondents (89\%) were more than the males and referred more to the physician and healthcare team.

\section{Conclusion}

This study showed that there was a noticeable gap between the patients' expectations and their perception from SQs provided in family physician program in all dimensions. We can fill these gaps by improving health centers' physical environment and facilities, using proper and up-to-date equipment, promoting personnel enthusiasm, performing educational sessions and better human resources management, with the objective of increasing the quality of health team services. Since we found the deepest gap in tangible and responsiveness dimensions, it is recommended to consider the physical appearance of the health center environment and personnel, prompt attention to on time services and availability of the personnel. We emphasize on continuous improvement through studies on patients' behavior and their expectation, their needs and problems to reach a higher level of services quality in family physician plan.

\section{Acknowledgments}

This study was the result of a research proposal, which was accepted by the research chancellor of Mashhad University of Medical Sciences (Grant No. 910286). Researchers appreciate the help and supports of Khorasan Razavy Health Center, rural health centers in Mashhad regions 1,2, 3, and 5; and also staff of rural health homes.

\section{Ethical issues}

The study was approved by the ethic committee of Mashhad University of Medical Sciences.

\section{Competing interests}

The authors declare that they have no competing interests. 
Authors' contributions

AV-N, HE, and ZN contributed to conceiving and designing the study. The data was collected by ZN, SHK, AP, and YM-T; and was analyzed and interpreted jointly by $\mathrm{ZN}, \mathrm{HE}$, and MV. Both $\mathrm{ZN}$ and $\mathrm{HE}$ contributed equally in writing the manuscript and all authors had an equal share in revising and approving the manuscript.

\section{Authors' affiliations}

${ }^{1}$ Health Sciences Research Center, Health and Management Department, School of Health, Mashhad University of Medical Sciences, Mashhad, Iran. 2Student Research Committee, Health and Management Department, School of Health, Mashhad University of Medical Sciences, Mashhad, Iran. ${ }^{3}$ Department of Health Services Management, School of Health Management and Information Sciences, Iran University of Medical Sciences, Tehran, Iran. ${ }^{4}$ Department of Health and Management, School of Health, Shiraz University of Medical Sciences, Shiraz, Iran. ${ }^{5}$ Sabzevar University of Medical Sciences, Sabzevar, Iran

\section{References}

1. World Health Organization (WHO). Primary Health Care. report of the international conference on primary health care. Geneva: WHO; 1978

2. Khayyati F, Motlagh ME, Kabir M, Kazemeini H, Gharibi F, Jafari $\mathrm{N}$. The role of family physician in case finding, referral, and insurance coverage in the rural areas. Iran J Public Health 2011; 40: 136-9.

3. Khuwaja AK, Khuwaja NK. Screening for diseases in family practice. J Pak Med Assoc 2005; 55: 116-8.

4. Raeissi P, Hashemi S. The Effect of Implementing the Family Physician Program on Prenatal Care Given to Rural Women at Fouman Health Network, North of Iran. American Journal of Scientific Research 2011: 134-43.

5. Hatam N, Joulaei H, Kazemifar Y, Askarian M. Cost efficiency of the family physician plan in fars province, southern iran. Iran $\mathrm{J}$ Med Sci 2012; 37: 253-9.

6. Mohammadi A, Mohammadi J. Evaluating quality of health services in health centres of Zanjan district of Iran. Indian J Public Health 2012; 56: 308-13.

7. Abu-Kharmeh S. Evaluating the Quality of Health Care Services in the Hashemite Kingdom of Jordan. International Journal of Business and Management 2012; 7: 195.

8. Parasuraman A, Zeithaml VA, Berry LL. SERVQUAL: A multipleitem scale for measuring consumer perceptions of service quality. Journal of Retailing 1988; 64: 12-40.

9. Laith A, Feras Ai. The Mediating Effect of Patient Satisfaction in the Patients' Perceptions of Healthcare Quality - Patient Trust Relationship. International Journal of Marketing Studies 2011; 3: 103-27.

10. Lin HC, Xirasagar S, Laditka JN. Patient perceptions of service quality in group versus solo practice clinics. Int $J$ Qual Health Care 2004; 16: 437-45.

11. Zarei A, Arab M, Froushani AR, Rashidian A, Ghazi Tabatabaei SM. Service quality of private hospitals: the Iranian patients' perspective. BMC Health Serv Res 2012; 12: 31.

12. Karassavidou E, Glaveli N, Papadopoulos CT. Quality in NHS hospitals: No one knows better than patients. Measuring Business Excellence 2009 13: 34-46.

13. Nekoei-Moghadam M, Amiresmaili M. Hospital services quality assessment: hospitals of Kerman University of Medical Sciences, as a tangible example of a developing country. Int $J$ Health Care Qual Assur 2011; 24: 57-66.

14. Farzady F, Mohammad K, Mafton f, Ghasemi R. [Number of physicians in the country and the possible implementation of the family physician workforce]. Payesh 2010; 8: 415-21.

15. Suki NM, Lian JC. Do patients' perceptions exceed their expectations in private healthcare settings? Int $J$ Health Care Qual Assur 2011; 24: 42-56.

16. Arab M, Tabatabaei SG, Rashidian A, Forushani AR, Zarei E. The Effect of Service Quality on Patient loyalty: a Study of Private Hospitals in Tehran, Iran. Iran J Public Health 2012; 41: 71-7.

17. Yousapronpaiboon K, Johnson WC. Out-patient Service Quality Perceptions in Private Thai Hospitals. International Journal of Business and Social Science 2013; 4: 57-66.

18. De Jager J, Du Plooy T. Are Public Hospitals Responding to Tangible and Reliable Service-Related Needs of Patients in the New South Africa? Journal of Management Policy and Practice 2011; 12: 103.

19. Peer M, Mpinganjira M. A gap analysis of service expectations and perceptions in private general practice. African Journal of Business Management 2012; 6: 297.

20. Aghamolaei T, Zare S. Quality gap of educational services in viewpoints of students in Hormozgan University of medical sciences. BMC Med Educ 2008; 8: 34.

21. Sohail SM. Service quality in hospitals: more favorable than you might think. Managing Service Quality 2003; 13: 197-206.

22. Yesilada F, Direktor E. Health care service quality: Acomparison of public and private hospitals. African Journal of Business Management 2010; 4: 962-71.

23. Dean AM. The applicability of SERVQUAL in different health care environments. Health Mark Q 1999; 16: 1-21.

24. Van Duong D, Binns CW, Lee AH, Hipgrave DB. Measuring clientperceived quality of maternity services in rural Vietnam. Int J Qual Health Care 2004; 16: 447-52.

25. Jenaabadi H, Abili K, Nastiezaie N, Yaghubi Noor M. [The gap between perception and expectations of patients of quality of treatment centers in Zahedan by using the Servqual model]. Payesh 2011 10: 449-57.

26. Dewi FD, Sudjana G, Oesman YM. Patient satisfaction analysis on service quality of dental health care based on empathy and responsiveness. Dent Res J (Isfahan) 2011; 8: 172-7.

27. Bestvater D, Dunn EV, Townsend C, Nelson W. Satisfaction and wait time of patients visiting a family practice clinic. Can Fam Physician 1988; 34: 67-70.

28. Kaldenberg DO. Patient satisfaction and health status. Health Mark Q 2001; 18: 81-101.

29. Szyca R, Rosiek A, Nowakowska U, Leksowski K. Analysis of factors influencing patient satisfaction with hospital treatment at the surgical department. Pol Przegl Chir 2012; 84: 136-43. 


\section{Key Messages}

Implications for policy makers

- Tangible dimension of quality is the first priority in any intervention to improve the quality of services in family physician services, so it is recommended to consider physical appearance of health center environments and personnel, prompt attention on timely services, and availability of personnel.

- Responsiveness and reliability are the second priority for intervention to improve the quality of services in this area.

- Assurance and empathy are the third priority for intervention in any quality improvement initiatives.

- Better service quality by health team is accessible by: improving the physical environment and facility, using proper and more sophisticated equipment, promoting personal motivation to work in rural area, performing educational session to improve the human resource capability and improving the human resource management.

- Continuous improvement through studies on patients' behavior and their expectation, their needs and problems is recommended to reach a higher level of services quality in family physician plan.
Implications for public

There was a great gap between the ideal situation and the current situation of family physician quality of services. We suggest having strong focus on patients, creating medical practice that would exceed patients' expectations, providing high-quality healthcare services, and assuring continuous improvement of all processes. In both tangible and responsiveness, the gap was greater than the other dimensions. Paying more attention to the physical appearance of the health centers' environment and the availability of staff and employees, by reducing the gap between patients' perceptions and expectations of health services will increase their satisfaction. 